\title{
AN EXPERIMENTAL INVESTIGATION OF FLOW OVER PENTAGONAL CYLINDER
}

\author{
Kapil Ghosh*, Md. Quamrul Islam and Mohammad Ali \\ Department of Mechanical Engineering, \\ Bangladesh University of Engineering and Technology (BUET), Dhaka-1000, Bangladesh \\ *Corresponding e-mail:kapil_chaity@yahoo.com
}

\begin{abstract}
In this research work, an experimental investigation of wind effect on pentagonal cylinders was carried out. The study was performed on the single cylinder in an open circuit wind tunnel at a Reynolds number of $4.22 \times 10^{4}$ based on the face width of the cylinder across the flow direction in a uniform flow velocity of $13.5 \mathrm{~m} / \mathrm{s}$. The test was carried out at various angles of attack from $0^{\circ}$ to $63^{\circ}$ at a step of $9^{\circ}$. The surface static pressures at the different locations of the cylinder were measured with the help of inclined multi-manometers. The wind velocity was kept constant at $13.5 \mathrm{~m} / \mathrm{s}$. The pressure coefficients were calculated from the measured values of the surface static pressure distribution on the cylinder. Later the drag and lift coefficients were obtained from the pressure coefficients by the numerical integration method. The results will enable the engineers and architects to design buildings more efficiently. Since the results will be expressed in the nondimensional form they may be applied for the prototype building.
\end{abstract}

Keywords: Drag coefficient, lift coefficient, pentagonal cylinder, pressure distribution, wind load.

NOMENCLATURE

A Frontal area of the Cylinder

$F_{D}$ Drag force

$F_{L} \quad$ Lift force

$\mathrm{C}_{\mathrm{L}}$ Coefficient of lift

$\mathrm{C}_{\mathrm{D}}$ Coefficient of drag

$\mathrm{C}_{\mathrm{P}}$ Coefficient of pressure

$\mathrm{P} \quad$ Pressure on the surface of the cylinder

$\mathrm{P}_{\mathrm{o}}$ The ambient pressure

$\mathrm{P}$ The density of the air

$\mathrm{U}_{\infty}$ The free stream velocity

\section{INTRODUCTION}

The subjects of wind load on buildings and structures are not a new one. In the $17^{\text {th }}$ century, Galileo and Newton have considered the effect of wind loading on buildings, but during that period, it did not gain popularity. The effect of wind loading on buildings and structures has been considered for design purposes since late in the $19^{\text {th }}$ century; but starting from that time up to about 1950, the studies in this field have not been considered seriously. Building and their components are to be designed to withstand the code specified wind loads. Calculating wind loads is important in the design of wind force resisting system, including structural members, components, and cladding against shear, sliding, overturning, and uplift actions. In recent years, much emphasis has been given on "The study of wind effect on buildings and structures" in the different corners of the world. Even researchers in Bangladesh have taken much interest in this field. Till now, little attention has been paid to the flow over the bluff bodies like square cylinders, rectangular cylinders, hexagonal cylinders, octagonal cylinders etc. and

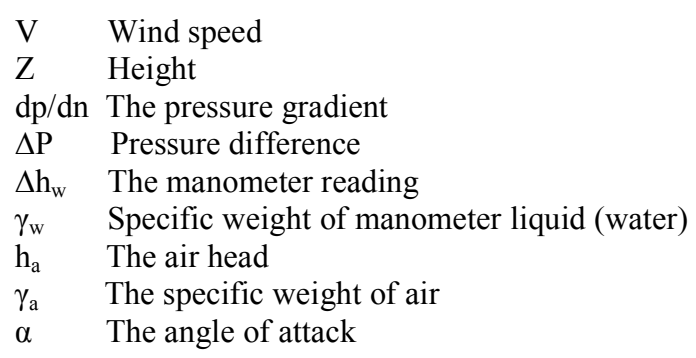

some information is available concerning the flow over them in staggered condition, although this is a problem of considerable practical significance. With the progressing world, Engineering problems regarding wind loads around a group of skyscrapers, chimneys, towers and the flow induced vibration of tubes in heat exchangers, bridges, oil rigs or marine structures need detailed investigation of flow patterns and aerodynamic characteristics.

Arising from the increasing practical importance of bluff body aerodynamics, over the past few decades' sufficient effort has been given in research works concerning laboratory simulations, full-scale measurements and more recently numerical calculations and theoretical predictions for flows over bodies of wide variety of shapes. A number of failures of bridges, transmission towers, buildings and housings over the last one hundred years prompted researchers to do research work in this field.

It is the great challenge of the engineers and architects to reduce the wind load on the tall buildings. Nowadays due to huge population pressure, emphasis on design and construction of the 
tall buildings is being given in many places. Especially the design of the group of tall buildings is the most important consideration to take care of the housing problem of the huge population. As the building becomes tall it is necessary to take into consideration the effect of wind on its design. Keeping this in mind the study on the pentagonal cylinder has been conducted, which will be applicable to obtain the wind load on the tall buildings. The study of wind effect was first limited to loading on buildings and structures only, possibly because of its most dramatic effects are seen in their collapses. In mid-sixties, researchers started the study of less dramatic, but equally important environmental aspects of flow of wind around buildings. These include the effects on pedestrians, weathering, rain penetration, ventilation, heat loss, wind noise and air pollution etc. The pioneer researcher in this field is Lawson, T.V. ${ }^{1}$ of the University of Bristol. A number of works of the environmental aspects of wind was being studied at the Building Research Establishment at Garson and the University of Bristol, UK.

It is true that researchers from all over the world have contributed greatly to the knowledge of flow over bluff bodies as published by Mchuri, F. G. ${ }^{2}$ but the major part of the reported works are of fundamental nature involving the flow over single body of different profiles. Most of the researchers have conducted works either on single cylinder with circular, square, octagonal, hexagonal or rectangular sections etc. or in a group with them for various flow parameters. However, the flow over a pentagonal cylinder has not been studied extensively, although this is a problem of practical significance. It is believed that the study on the cylinder with pentagonal section will contribute to find the wind load on the single pentagonal building and the results will be useful to the relevant engineers and architects. There are various parameters, which control the flow behavior as mentioned by Castro, J.P. ${ }^{3}$. They are (i) vortices in front of the building, (ii) opening through buildings, (iii) spacing of rows, (iv) wakes of buildings, (v) long straight streets, (vi) narrowing streets; (vii) corners and (viii) courtyards. The mean wind speed varies with height. The variation of wind speed has been expressed by Davenport, A. G. ${ }^{4}$. The wind in the atmospheric boundary layer varies in time and space. The source of wind energy is the sun that emits solar radiation, which causes differential heating of the earth surface and the atmosphere.

In the atmosphere there is a general convective transport of heat from lower to higher latitudes in order to make the earth's radiation imbalance as mentioned by Lanoville, A. ${ }^{5}$. It is for this reason that the atmosphere is a restless medium in which circulation of all sizes is normal. Lee ${ }^{6}$ performed study on the effect of turbulence on the surface pressure field on a square prism. In his study, measurements were presented of the mean and fluctuating pressure field acting on a two dimensional square cylinder in uniform and turbulent flows. In his investigation he showed that the addition of turbulence reduces the drag on the cylinder. Mandal and Farok $^{7}$ measured the static pressure distributions on the single cylinder with square and rectangular cross-section having rounded corners in a uniform cross flow. The experiment was conducted for different corner radii and side dimensions of the cylinders at zero angle of attack. The experimental results reveal that the corner radius of the cylinder has significant effect while the side dimension has some effect on the drag coefficient.

Mandal and Islam $^{8}$ made an experimental investigation of mean pressure coefficients on square cylinders. They measured the pressure coefficients on single square cylinder at various angles of attack and on a group of square cylinders with sharp edge at zero angle of attack. Islam and $\mathrm{Mandal}^{9}$ performed an experimental investigation of static pressure distributions on a group of rectangular cylinders in a uniform cross flow. The effect of longitudinal spacing as well as the side dimension of the cylinder was taken into consideration in the study.

It is the task of the engineer to ensure that the performance of structures subjected to the action of wind will be adequate during their anticipated life from the standpoint of both structural safety and serviceability. To achieve this end, the designer needs information regarding (i) the wind environment, (ii) the relation between that environment and the forces it induces on the structures, (iii) the behavior of the structure under the action of forces. The knowledge of wind loading on a single tall building or on a group of tall buildings is essential for their economic design. The flow around a pentagonal model cylinder can be ideally considered analogous to that of the flow around a tall pentagonal-shaped building. Therefore, a study of wind flow around pentagonal cylinder would be helpful in this respect. The wind in the atmospheric boundary layer varies in time and space. It depends on the terrain roughness, the local wind climate and on variations in temperature. Usually the effects of temperature are assumed negligible, when studying wind loads relevant are the proper simulation of the wind speed with height and the turbulent characteristics.

The wind tunnel testing provides information regarding the dependence of particular response parameters on wind speed and direction. In order to make the most rational use of this aerodynamic information, it is necessary to synthesize it with the actual wind climate characteristics at the site. The characteristics necessary to define are those 
governing wind speed and direction at a suitable height above ground level at the site. The joint probability distribution of wind speed and direction then defines the wind climate, whereas all of the aerodynamic information, which includes sensitivities to building orientation and to its surroundings, is contained in the wind tunnel data. Though the problem regarding the wind loadings on buildings and structures is common to all parts of the world and it is expected that the solution will not be significantly different from country to country, yet research work should be carried out in this field considering the climatic conditions and problem of this country so that a clear picture about the nature of wind loading can be obtained. The data from these research works should enable to the architects, engineers and town planners of Bangladesh to design buildings and structures more efficiently.

The scale difference between wind tunnel model and prototype is found in the high frequency fluctuation. High peaks found on the cladding in fullscale are not found in the wind tunnel. Those effects may be caused by structural details that are not simulated in the wind tunnel model. Now-a-days, both the studies with models and full-scale buildings are being performed to compare the result for varying the validity of the former. But full-scale experiments are both costly and difficult to perform. For the present study full- scale experiments will not only be complex and costly but it would be difficult to record reliable pressure distribution on the buildings as there will be variation of speeds and direction of wind with time. The flow around buildings in actual environment is very complex and formulation of a mathematical model to predict the flow is almost impossible. Thus model study is a must and the results obtained under simulated condition in the laboratory are found to be quite satisfactory for practical purposes.

\section{EXPERIMENTAL SETUP Wind tunnel}

The test was conducted at the exit end of an open circuit subsonic wind tunnel. In Fig. 1 the schematic diagram of the wind tunnel is presented showing the position of the cylinder at the exit end of the wind tunnel in a uniform cross flow. The wind tunnel was $5.93 \mathrm{~m}$ long with a test section of $460 \mathrm{~mm} \times 460 \mathrm{~mm}$ cross section. The cylinder was fixed to the side walls of the extended portion at the exit end.

In the side wall the cylinder was fastened rigidly at one end and through the other end of the cylinder the plastic tubes from the tapping were taken out and were connected with the inclined multi-manometer, which contained water as the manometer liquid. The cylinder was leveled in such a way that the top face of the pentagonal cylinder was parallel to the flow direction. The axis of the cylinder was at the same level to that of the wind tunnel. To generate the wind velocity, two axial flow fans are used. Each of the fans is connected with the motor of 2.25 kilowatt and $2900 \mathrm{rpm}$. The induced flow through the wind tunnel is produced by two-stage rotating axial flow fan of capacity $18.16 \mathrm{~m}^{3} / \mathrm{s}$ at the head of $152.4 \mathrm{~mm}$ of water and $1475 \mathrm{rpm}$.

In each case of the tests, wind velocity is measured directly with the help of a digital anemometer. The flow velocity in the test section was maintained at $13.5 \mathrm{~m} / \mathrm{s}$ approximately. The measured velocity distribution was almost uniform across the tunnel test section in the upstream side of the test models.

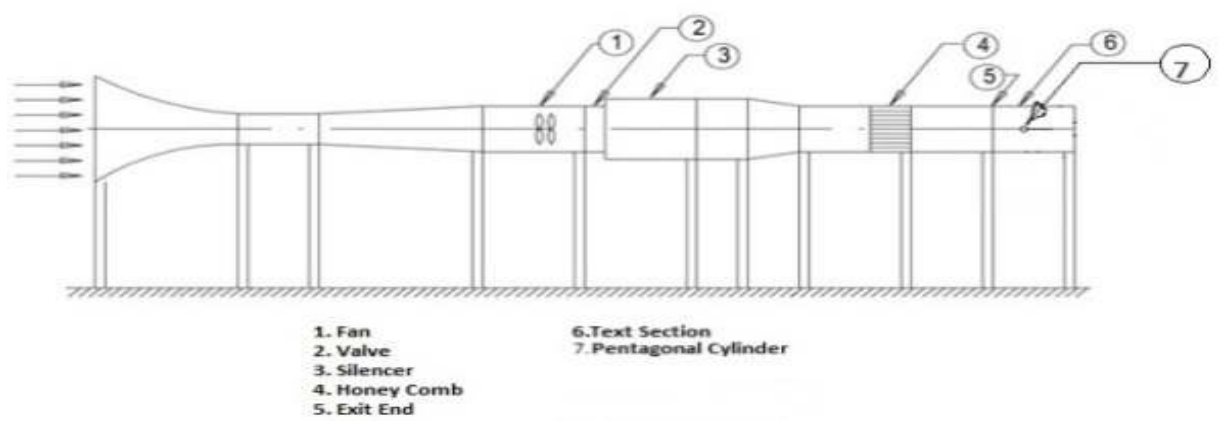

Figure 1. Schematic diagram of wind tunnel.

The pattern of the flow velocity is shown in Fig. 2 in the non-dimensional form. The values of $U / U_{\infty}$ and $\mathrm{h} / \mathrm{H}$ were matched with each other. The most obvious quantity that can be measured with the Pitot-static probe is the velocity distribution in the upstream side of the test models. The following figure shows the velocity distribution across the test section.
There was a provision for rotation of the test cylinder at various angles to obtain the wind load at different angles of attack. The Reynolds number was $4.22 \times 10^{4}$ based on the projected width of the cylinder across the flow direction. Since the top and bottom of the extended part of the wind tunnel was open; as such no correction for blockage was done in the analysis. The test cylinders were placed very close to 
the end of the wind tunnel so that the approach velocity on the test cylinders was approximately identical as that in the exit end of the wind tunnel.

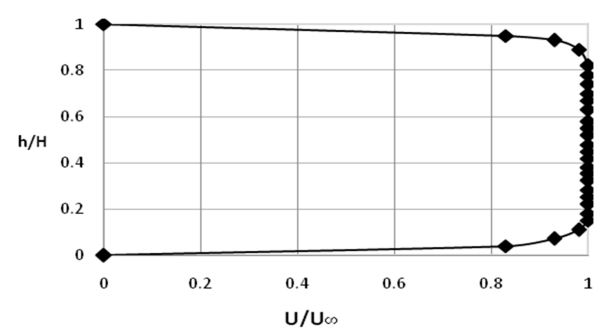

Figure 2. Velocity distribution at upstream side of model cylinder.

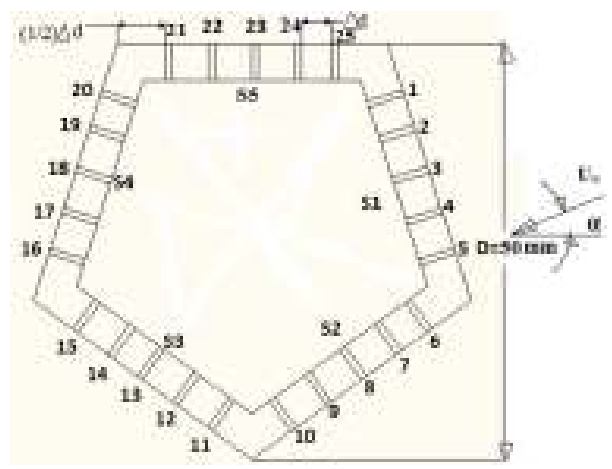

Figure 3. Tapping positions shown on cross-section of cylinder.

\section{Constructional details of cylinders}

The tapping positions on the cross-section of the cylinder are shown in Fig. 3. The width of the pentagonal cylinder was $50 \mathrm{~mm}$ as shown in the figure. Each face of the cylinder contained five tappings.

In Fig. 4 the tapping positions on the longitudinal section of the cylinder is shown. There were five tappings on each face of the cylinder. The distance between the consecutive tapping points was equal $(\Delta \mathrm{d})$ as shown in the figure. However, the location of the corner tapping was at a distance of $\frac{1}{2} \Delta \mathrm{d}$. Each tapping was identified by a numerical number from 1 to 25 for pentagonal cylinder as can be seen from the figure. It can be seen from the longitudinal section that the tappings were not made along the crosssection of the cylinder. They were located within some span of the cylinder as shown in Figure 4. On one side of the cylinder a steel plate was attached through which there was a bolt for fixing the cylinder with the side wall of the extended tunnel as shown in Figure 4 . The other side of the cylinder was hollow through which the plastic tubes were allowed to pass. The plastic tubes were connected with the copper capillary tubes at one side and at the other side with the inclined multi-manometer. The manometer liquid was water. The tappings were made of copper tubes of $1.71 \mathrm{~mm}$ outside diameter. Each tapping was of $10 \mathrm{~mm}$ length approximately. From the end of the copper tube flexible plastic tube of $1.70 \mathrm{~mm}$ inner diameter was press fitted.

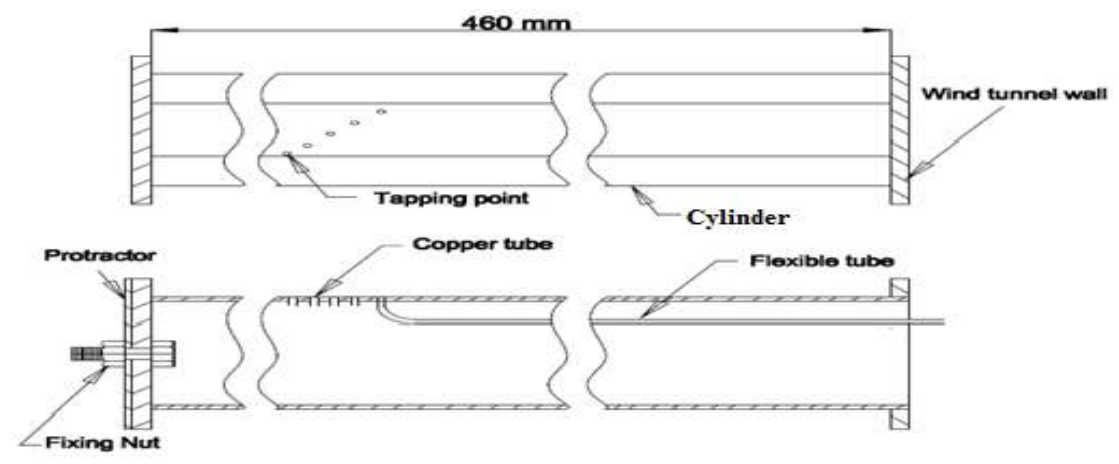

Figure 4. Tapping positions shown on longitudinal section of cylinder.

\section{Single cylinder}

The upstream velocity was assumed to be uniform and the flow occurred across the cylinder. In Fig. 5 the position of the single cylinder at zero angle of attack is shown in the wind tunnel test section.

The surface static pressure distributions on faces of the cylinder were measured in this position. Then the cylinder was rotated at an angle of $9^{0}$ for pentagonal cylinder and the static pressure distribu-

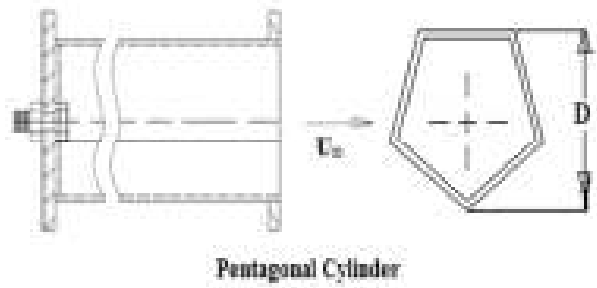

Figure 5. Tunnel test section showing position of single cylinder.

Journal of Mechanical Engineering, Vol. ME 44, No. 1, June 2014

Transaction of the Mechanical Engineering Division, The Institution of Engineers, Bangladesh 
-tions on each face of the cylinder were measured again. The same test procedure was repeated to measure the surface static pressure distributions of the cylinders with angles of attack of $0^{\circ}, 9^{0}, 18^{\circ}, 27^{\circ}$, $36^{\circ}, 45^{\circ}, 54^{\circ}$ and $63^{\circ}$ for pentagonal cylinder.

MATHEMATICAL MODEL

The pressure coefficient is defined as

$$
C_{P}=\frac{\Delta \mathrm{P}}{\frac{1}{2} \rho U_{\infty}^{2}}
$$

Drag and lift coefficients are defined as follows

$$
C_{D}=\frac{F_{d}}{\frac{1}{2} \rho A U_{\infty}^{2}} \text { and } C_{L}=\frac{F_{L}}{\frac{1}{2} \rho A U_{\infty}^{2}}
$$

\section{RESULTS AND DISCUSSION \\ Single Cylinder}

In this section the distributions of the pressure coefficients, drag and lift coefficients have been taken into consideration for discussion for a single pentagonal cylinder at different angles of attack. Pressure coefficients have been calculated from the measured values of the surface static pressures. Then the drag and lift coefficients have been obtained from the pressure coefficients by the numerical integration method. All the coefficients are determined for the uniform cross flow on the cylinder at Reynolds of $4.22 \times 10^{4}$ based on the width of the cylinder across the flow direction at zero angle of attack.

\section{Distribution of pressure coefficient}

The cross-section of the single pentagonal model cylinder with 25 numbers of tappings, five numbers on each surface of the cylinder at an angle of attack has been shown in Fig. 3. The five surfaces have been identified with $\mathrm{S}_{1}, \mathrm{~S}_{2}, \mathrm{~S}_{3}, \mathrm{~S}_{4}$ and $\mathrm{S}_{5}$. Pressure coefficient for each tapping point has been determined from the measured surface static pressure. In Figures 6 to 13, the distributions of static pressure coefficients for angles of attack of $0^{\circ}$ to $63^{\circ}$ with a step of $9^{\circ}$ have been presented respectively.

From Fig. 6 one can observe that on surface $S_{2}$, there is stagnation point on tapping point 7 at zero angle of attack. It can be further noticed from this figure that the pressure coefficient values are positive on the all surfaces. However, one interesting point can be seen from this figure that almost uniform pressure coefficient distributions are found on surfaces $\mathrm{S}_{3}$ to $\mathrm{S}_{5}$.

In Fig. 7 at angle of attack of $9^{\circ}$, there is no stagnation point and the value of the pressure coefficient has increased slightly on surface $\mathrm{S}_{1}$, while it has dropped slightly on surface $\mathrm{S}_{2}$ and $\mathrm{S}_{5}$. However, on the other surfaces $\mathrm{S}_{3}$ and $\mathrm{S}_{4}$, the distributions of pressure coefficient are almost uniform. It can be further noticed from this figure that the pressure coefficient values are positive on the all surfaces except surface $\mathrm{S}_{5}$.

In Fig. 8 at angle of attack of $18^{\circ}$, there is no stagnation point and there is further rise of $\mathrm{C}_{p}$ values on surface $S_{1}$ and $S_{5}$ and further drop of $C_{p}$ values on surface $\mathrm{S}_{2}$. However, on surfaces $\mathrm{S}_{3}$ to $\mathrm{S}_{4}$ almost uniform $\mathrm{C}_{\mathrm{p}}$-distribution occurs.

At $\alpha=27^{\circ}$, one can be observed from Fig. 9, there is no stagnation point. However, there is almost uniform Cp-distribution on the surfaces $\mathrm{S}_{2}$ to $\mathrm{S}_{4}$.

In Fig. 10 at angle of attack of $36^{\circ}$, there is no stagnation point. On the surfaces $\mathrm{S}_{2}$ and $\mathrm{S}_{4}$, the distributions of pressure coefficient are almost uniform. It can be further noticed from this figure that the pressure coefficient values are positive on the all surfaces.

From Fig. 11 one can observe that the distribution of the pressure coefficients is symmetric at $\alpha=45^{\circ}$. It can be further noticed from this figure that nowhere there is stagnation point. It is due to the fact that the location at the stagnation point has not been selected for the tapping. The pressure coefficient values are positive on the all surfaces. However, one interesting point can be seen from this figure that almost uniform pressure coefficient distributions are found on surfaces $S_{2}$ to $S_{4}$.

In Fig. 12 at angle of attack of $54^{\circ}$, the value of the pressure coefficient has decreased slightly on surface $S_{1}$, while it has increased slightly on surface $S_{5}$. However, on the other three surfaces $S_{2}$ to $S_{4}$, the distributions of pressure coefficient are almost uniform. At $\alpha=54^{\circ}$, the $\mathrm{Cp}$-distribution is close to that at $\alpha=45^{\circ}$.

In Fig. 13 at angle of attack of $63^{\circ}$, the value of the pressure coefficient has decreased further on surface $S_{1}$, while it has increase slightly on surface $S_{5}$. However, on the other three surfaces $S_{2}$ to $S_{4}$, the distributions of pressure coefficient are almost uniform. It can be further noticed from this figure that nowhere there is stagnation point. The pressure coefficient values are positive on the all surfaces. Further rotation of the cylinder has not been made because at $\alpha=0^{\circ}$ and $\alpha=72^{\circ}$, they are identical.

\section{Variation of drag coefficient}

Variation of drag coefficient at various angles of attack on single pentagonal cylinder is shown in Figure 14. The drag coefficient at different angles of attack on a single square cylinder at uniform flow obtained by Mandal, A. C. ${ }^{7}$ is also presented in this figure for comparison. It can be noticed from this figure that there is significant drop in the drag coefficient values for the pentagonal cylinder in comparison to that of the square cylinder. It is seen from this figure that at zero angle of attack, the drag coefficient is about 1.48 and at all other angles of attack, the values are close to 1.55 except at angle of 
attack of $9^{\circ}$ and $18^{\circ}$, where the value is about 1.30 and 1.22 respectively. The values of the drag coefficient at various angles of attack for the pentagonal cylinder can be explained from the Cpdistribution curves.

\section{Variation of lift coefficient}

In Fig. 15 the variation of lift coefficient at various angles of attack on single pentagonal cylinder is shown. The lift coefficient at different angles of attack on a square cylinder at uniform flow obtained by Mandal, A. C. ${ }^{7}$ is also presented in this figure for comparison. It can be noticed from this figure that the variation of the lift coefficient on the single pentagonal cylinder is shifted $9^{0}$ and pattern is more or less similar with the variation of lift coefficient for the single square cylinder except at angle of attack of $0^{\circ}$. The values of the lift coefficients for the single pentagonal cylinder can be explained from the $\mathrm{Cp}$-distribution curves.

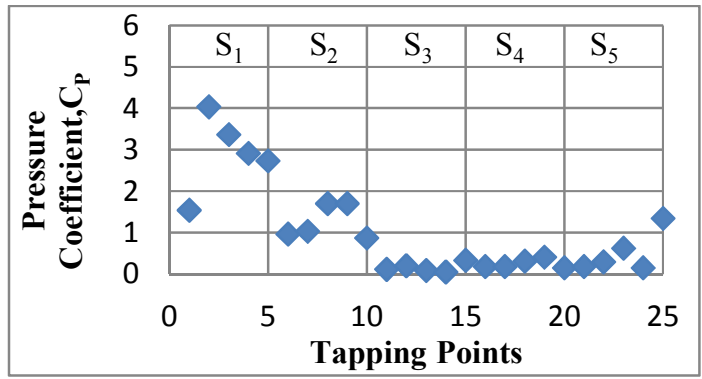

Figure 6. Distribution of Pressure Coefficient at Angle of Attack of $0^{0}$.

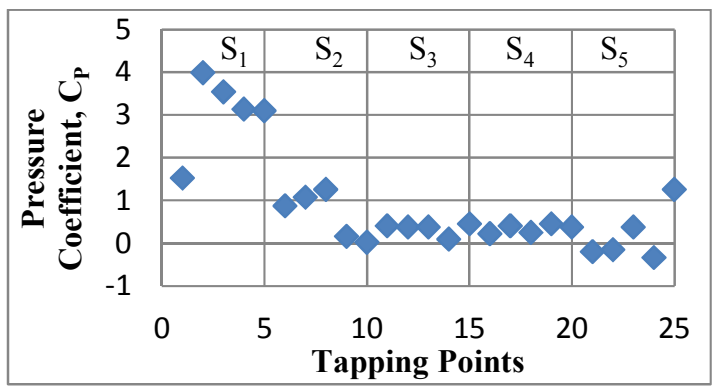

Figure 7. Distribution of Pressure Coefficient at Angle of Attack of $9^{0}$.

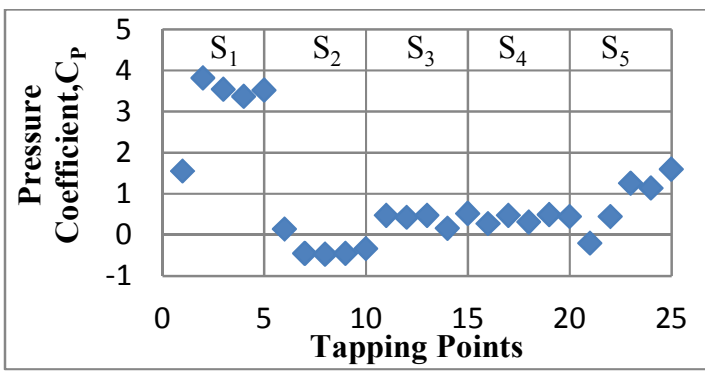

Figure 8. Distribution of Pressure Coefficient at Angle of Attack of $18^{0}$.

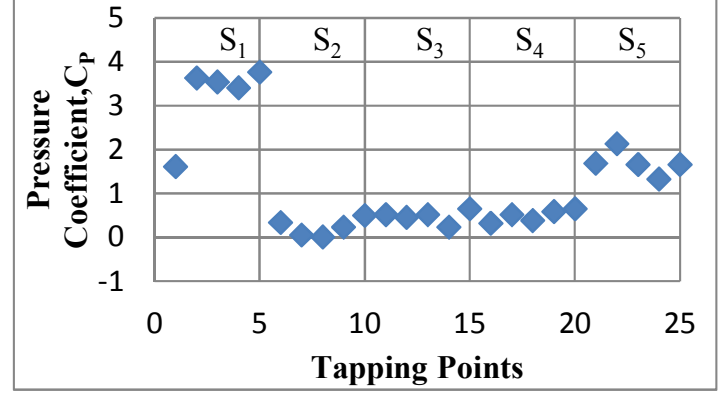

Figure 9. Distribution of Pressure Coefficient at Angle of Attack of $27^{0}$.

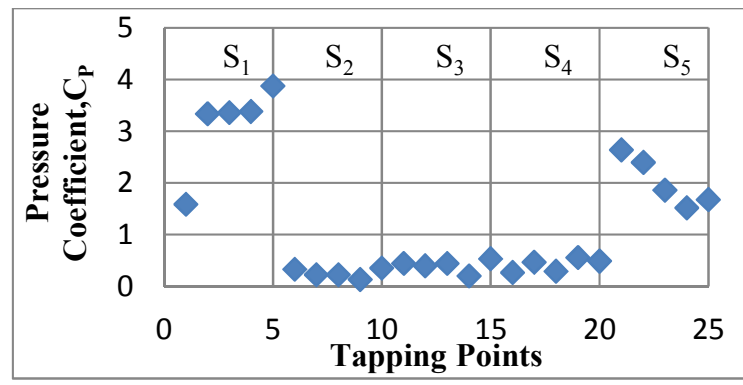

Figure 10. Distribution of Pressure Coefficient at Angle of Attack of $36^{0}$.

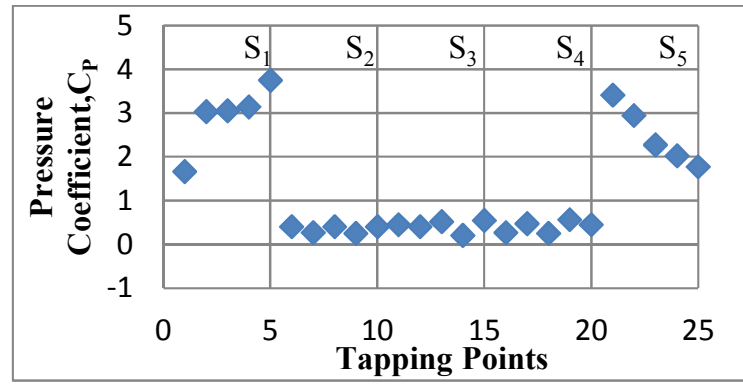

Figure 11. Distribution of Pressure Coefficient at Angle of Attack of $45^{\circ}$.

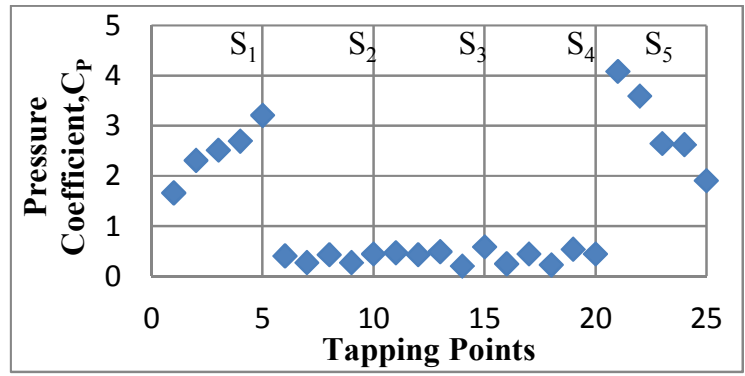

Figure 12. Distribution of Pressure Coefficient at Angle of Attack of $54^{0}$.

Journal of Mechanical Engineering, Vol. ME 44, No. 1, June 2014

Transaction of the Mechanical Engineering Division, The Institution of Engineers, Bangladesh 


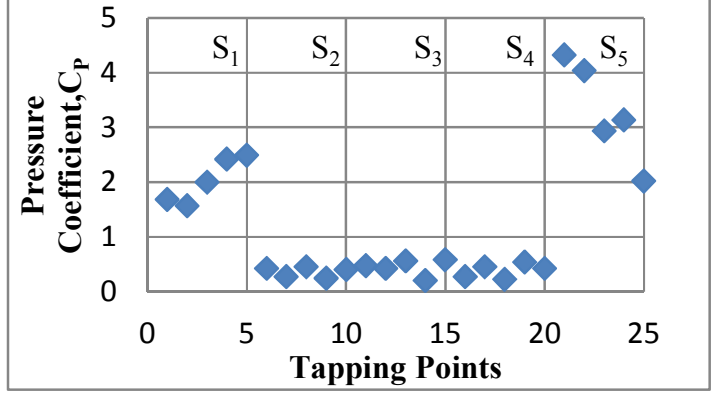

Figure 13. Distribution of Pressure Coefficient at Angle of Attack of $63^{0}$.

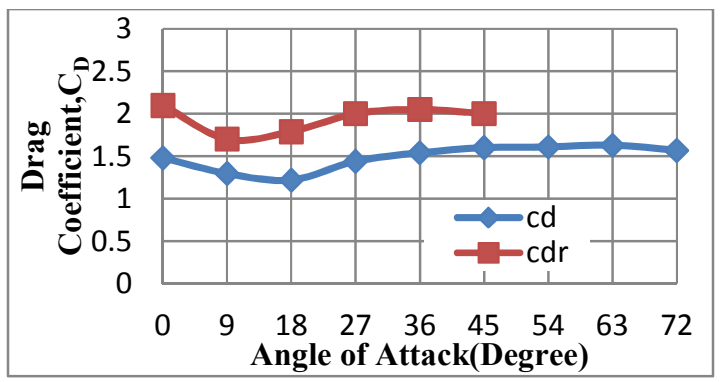

Figure 14. Variation of Drag Coefficient at Various Angles of Attack.

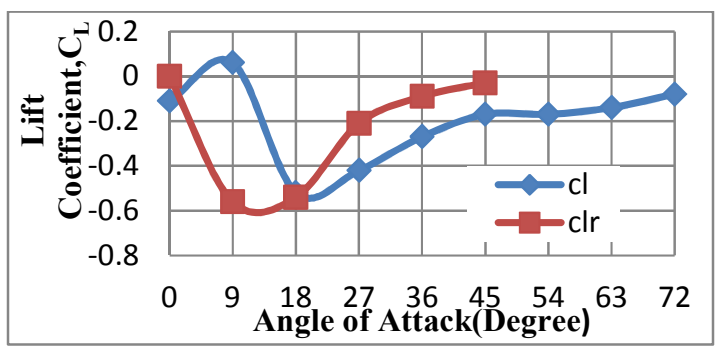

Figure 15. Variation of Lift Coefficient at Various Angles of Attack.

\section{CONCLUSIONS}

The following conclusions are drawn in regard to the wind effect on the single pentagonal cylinder. There is significant drop in the drag coefficient values for the single pentagonal cylinder in comparison to that of the single square cylinder. The drag coefficient for a single pentagonal cylinder at zero angle of attack is about 1.48 in contrast to that of 2.0 for a single square cylinder at the same angle of attack. The variation of the lift coefficient on the single pentagonal cylinder is shifted $9^{\circ}$ and pattern is more or less similar with the variation of lift coefficient for the single square cylinder except at angle of attack of $0^{\circ}$. The stagnation point is found on the front face of single pentagonal cylinder. While wind load is to be used for the design of the free- standing building having pentagonal cross-section, the outcome of the present results may be applied.

\section{ACKNOWLEDGEMENTS}

This research work was funded by Department of Mechanical Engineering, Bangladesh University of Engineering \& Technology.

\section{REFERENCES}

1. Lawson, T.V., "Wind Loading of Buildings, Possibilities from a Wind Tunnel Investigation", University of Bristol, U.K. Report on TVL /731A, 1975.

2. Mchuri, F.G. et al, "Effects of the free Stream Turbulences on Drag Coefficients of Bluff sharpEdged Cylinders", Nature, Vol. 224(5222), 1969, pp. 908-909.

3.Castro, J.P. and Fackwell, J.E., "A Note on TwoDimensional Fence Flows with Emphasis on Wall Constant", J. Industrial. Aerodynamics, 3(1), 1978.

4. Davenport, A.G., "The Relation to wind Structure to Wind Loading", Proc.of the Conference on Wind Effects on Buildings and Structures", Vol.1, 1963.

5. Lanoville, A., Gateshore, I.S. and Parkinsoon, G.V., "An Experimental of some effects of turbulence on bluff bodies", Proceeding of the $4^{\text {th }}$ international Conference on wind Effects on Buildings and Structure, London, U.K., 1975

6. Lee, B.E., "The Effect of Turbulence on the Surface Pressure Field of a Square Prism", Journal of Fluid Mechanics, Vol.6 J.E. 9,1975, pp. 263-282.

7. Mandal, A.C. and Farok, G.M.G., "An Experimental Investigation of Static Pressure Distributions on Square and Rectangular Cylinders with Rounded Corners", $4^{\text {th }}$ International Conference on Heat Transfer, Fluids Mechanics and Thermodynamics (HEFAT), Cairo, Egypt, 2005.

8. Islam, A.T.M. and Mandal, A.C., "Experimental Analysis of Aerodynamic Forces for Cross- flow on single Rectangular Cylinder", Mechanical Engineering Research Bulletin, BUET, Dhaka, Vol.13(1), 1990, pp. 36-51.

9. Islam, A.M.T. and Mandal, A.C., "Static Pressure Distribution for Cross- flow on single Rectangular Cylinders", Mechanical Engineering Research Bulletin, BUET, Dhaka, Vol.14(1), 1991, pp.8-23.

10. Mandal, A.C.and Islam, O., "A Study of Wind Effect on a Group of Square Cylinders with Variable Transverse and Longitudinal Spacing", The Institution of Engineers, Bangladesh, Vol. 9(1), 1981, pp.33-39. 